\title{
Drug-free tracheal intubation by specialist paramedics (critical care) in a United Kingdom ambulance service: a service evaluation
}

Silas Houghton Budd*iD, Eleanor Alexander-Elborough, Richard Brandon, Chris Fudge, Scott Hardy, Laura Hopkins, Ben Paul, Sloane Philips, Sarah Thatcher and Paul Winsor

\begin{abstract}
Background: Drug-free tracheal intubation has been a common intervention in the context of out-of-hospital cardiac arrest for many years, however its use by paramedics has recently been the subject of much debate. Recent international guidance has recommended that only those achieving high tracheal intubation success should continue to use it.

Methods: We conducted a retrospective service evaluation of all drug-free tracheal intubation attempts by specialist paramedics (critical care) from South East Coast Ambulance Service NHS Foundation Trust between 1st January and 31st December 2019. Our primary outcome was first-pass success rate, and secondary outcomes were success within two attempts, overall success, Cormack-Lehane grade of view, and use of bougie.

Results: There were 663 drug-free tracheal intubations and following screening, 605 were reviewed. There was a first-pass success rate of $81.5 \%$, success within two attempts of $96.7 \%$, and an overall success rate of $98.35 \%$. There were ten unsuccessful attempts (1.65\%). Bougie use was documented in $83.4 \%$ on the first attempt, $93.5 \%$ on the second attempt and $100 \%$ on the third attempt,
\end{abstract}

Conclusion: Specialist paramedics (critical care) are able to deliver drug-free tracheal intubation with good first-pass success and high overall success and are therefore both safe and competent at this intervention.

Keywords: Tracheal intubation, Intubation, Airway, Paramedic, Prehospital, Critical care

\section{Introduction \\ Background}

Tracheal intubation (TI) is a common intervention in critical care medicine and is indicated for a number of reasons, including airway protection in comatose patients or those at risk of aspiration, facilitation of mechanical ventilation, and in anticipation of a deteriorating clinical course that will very likely lead to

\footnotetext{
* Correspondence: silas.houghton@secamb.nhs.uk

Critical Care Operating Unit, South East Coast Ambulance Service NHS Foundation Trust, Nexus House, 4 Gatwick Road, Crawley RH10 9BG, UK
}

respiratory failure [15]. In prehospital emergency medicine, TI is used in the context of both prehospital emergency anaesthesia or without anaesthetic drugs in the context of out-of-hospital cardiac arrest (OHCA) - drug-free tracheal intubation (DF-TI). While paramedic-led anaesthesia is delivered safely and effectively abroad [8], in the United Kingdom (UK) it is currently restricted to physician-led services, such as air ambulance charities [1] [16].

Drug-free tracheal intubation in the context of OHCA has been a core intervention for paramedics in the UK

(c) The Author(s). 2021 Open Access This article is licensed under a Creative Commons Attribution 4.0 International License, which permits use, sharing, adaptation, distribution and reproduction in any medium or format, as long as you give appropriate credit to the original author(s) and the source, provide a link to the Creative Commons licence, and indicate if changes were made. The images or other third party material in this article are included in the article's Creative Commons licence, unless indicated otherwise in a credit line to the material. If material is not included in the article's Creative Commons licence and your intended use is not permitted by statutory regulation or exceeds the permitted use, you will need to obtain permission directly from the copyright holder. To view a copy of this licence, visit http://creativecommons.org/licenses/by/4.0/ The Creative Commons Public Domain Dedication waiver (http://creativecommons.org/publicdomain/zero/1.0/) applies to the data made available in this article, unless otherwise stated in a credit line to the data. 
for over 30 years and is indicated when less invasive methods of airway care (such as supraglottic airway devices) are deemed suboptimal, although there is ongoing debate about both its safety and efficacy [21]. In 2015, the European Resuscitation Council [28] recommended TI as the most reliable method of securing the airway in OHCA, however also highlighted that there were no reliable data showing increased survival with this method and went on to recommend the use of a supraglottic airway device as an acceptable alternative. Given the lack of survival benefit associated with TI and the efficacy of supraglottic airway devices, the most recent consensus from the International Liaison Committee on Resuscitation recommended a supraglottic airway device for OHCA in settings with "low TI success" and supraglottic airway device or TI for OHCA in settings with "high TI success" but did not define "high" or "low" [27]. The most recent European Resuscitation Council and Resuscitation Council UK guidelines $[25,26]$ recommend that those with a high TI success rate should use TI and define this as greater than $95 \%$ within two attempts. Given supraglottic airway devices are now so widely available, a recent consensus statement from the College of Paramedics $[4,5]$ in the UK recommended that only paramedics with ongoing education, training, and clinical governance should perform TI, a recommendation which is emphasised by Soar et al. [26].

Tracheal intubation can be a complex procedure and may lead to unrecognised oesophageal intubation, long pauses in closed chest compressions, prolonged durations of hypoxia, or other complications if not achieved quickly [2]. Evidence suggests that multiple attempts at TI are associated with an increased risk of adverse events [11] and as such, first-pass success - successful placement of the tracheal tube in the trachea following the first attempt at laryngoscopy and confirmed by waveform capnography - is a recognised standard against which TI success is measured [24]. In the recent, large 'PART' trial $(n=3004)$ conducted in the United States of America, first-pass success in paramedic DF-TI was just 52\% [30] and second-pass success was not reported. Meanwhile, the concomitant 'AIRWAYS-2' trial in the UK $(n=9296)$ found success after up to two attempts to be $79 \%$ (and did not report first-pass success) [2].

Most paramedics in the UK attend an average of three OHCA per year [23] and as such, exposure to TI is likely to be low. However, the advent of specialties in paramedic practice $[4,5]$ has led to the development of specialist paramedics in critical care (SPCC) who are specifically tasked to high acuity cases, including airway complications and OHCA. SPCCs in South East Coast Ambulance Service NHS Foundation Trust (SECAmb) have a minimum of 3 years' post-registration experience as a paramedic prior to a two-year postgraduate diploma in prehospital critical care in which they receive additional training and education on airway care, as well as six weeks of clinical placement in intensive care units and theatres where this learning is consolidated in practice. SPCCs also undertake regular simulation training in airway care and engage in structured clinical governance sessions where complex cases are discussed in detail.

The large international trials mentioned do not differentiate between specialist and non-specialist paramedics despite the differences in experience, education, and exposure which may affect DF-TI success. For instance, the most recent data from SPCCs in London Ambulance Service showed first-pass success of $90.8 \%$ and overall success of $96.4 \%$ [17]. These data suggest SPCCs may have higher DF-TI success than non-specialist paramedics however are only from one service in one geographical region. To further address this knowledge gap, we aimed to conduct a similar service evaluation of SPCCs in SECAmb.

\section{Methods \\ Aim}

We aimed to assess DF-TI success when performed by SECAmb SPCCs by conducting a retrospective database review.

\section{Study design}

This was a retrospective service evaluation using routinely collected data from the SECAmb clinical governance database - CCPBase [18]. This is a secure, online reporting system which stores anonymised, clinical reports for the benefit of audit, reflection, and learning.

\section{Settings}

SECAmb serves a geographical area of approximately 3600 mile $^{2}$ with a resident population of 4.5 million and a transient population of eight million [7]. Data were retrieved from CCPBase for the period between 1st January - 31st December 2019.

\section{Participants}

All patients receiving DF-TI by SPCCs were identified for analysis. Records with incomplete data or where the DF-TI was completed by a non-SPCC were excluded. As discussed, all CCPBase records are anonymised and only the relevant variables were exported for analysis.

\section{Outcomes}

The primary outcome was first-pass success, and secondary outcomes were success within two attempts, overall success, grade of laryngoscopy view, and use of bougie. 
The Cormack-Lehane classification system (CLCS) is the model used by SPCCs in SECAmb to document and communicate the anatomical view achieved by the rescuer during direct laryngoscopy. It classifies the view achieved with direct laryngoscopy from easy to difficult using the numbers 1-4 [6]. In addition to these four views, CСPBase has two further dropdown options: 'impossible' for when anatomy or injury precludes laryngoscopy and 'unrecognisable' for when a CLCS grade of view is not achieved.

The use of a bougie to optimise TI success has been widely accepted in prehospital care for a number of years and is recommended in SECAmb for this reason.

\section{Data sources / measurement}

CCPBase has a built-in proforma for documenting TI. Dropdown boxes are used to record the number of attempts, as well as other factors such as the grade of view achieved, size of bougie used, or the presence of airway soiling. During the period of data collection there was a disparity in the way in which SPCCs recorded DF-TI attempts. Some documented the number of attempts by SPCC only while others documented the number of attempts the patient received (including non-SPCC and SPCC). In addition to the dropdown boxes however there was a free text box alongside the proforma, in which SPCCs could document further details about the intervention, such as the person delivering each attempt at DF-TI. This was reviewed for further information about the person delivering the intervention to ensure accuracy of data.

\section{Bias}

A potential bias was present as all the authors are employed as SPCCs by SECAmb and thus had a vested interest in achieving positive results [29]. This may have led to a conscious or subconscious bias in the free text box analysis described previously as this may have been open to interpretation [13]. To account for this, cases where it was unclear who performed the intervention were excluded from analysis.

\section{Statistical methods}

Descriptive statistical analysis was undertaken to report means, medians, and percentages.

\section{Results}

\section{Participants}

A data flow diagram is available in Fig. 1. There were 663 DF-TI records recorded on CCPBase between 1st January - 31st December 2019. Of these, 513 (84.8\%) reported the use of a bougie, while the remainder had no reported bougie use. Fifty-eight records were excluded, 38 because the details were not documented, 13 in which TI was performed by non-SPCC, three in which TI was performed by student paramedics, one which was completed by another enhanced care team, and one which was intentionally placed in the oesophagus prior to DF-TI. In two records, the tracheal tube was documented as visibly in the trachea but without waveform capnography and the capnography device was subsequently identified as not having been functioning. These were excluded as although a successful intubation, they did not meet our definition for a successful TI which included a waveform capnogram. One of these was a grade 1 view while the other was a grade 2 so the results are unlikely to have affected our final analysis significantly. Following exclusion, there were 605 remaining records which were fully analysed.

\section{Descriptive data}

Median (range) age was 63 (0-98), mean (range) estimated weight was $84.7 \mathrm{~kg}(3-222)$, and there was a higher proportion of male patients than female (417; $69 \%)$. There were 15 paediatric patients $(0.2 \%)$, of which seven were below one year of age and three were between zero and five years of age.

\section{Main results}

The main results are available in Tables 1 and 2. TI success rate was $98.35 \%(n=595)$ overall. Of the ten unsuccessful TI attempts, none had documented failed ventilation. Four hundred and ninety-three were intubated on the first attempt (81.5\%), 92 on the second attempt $(15.2 \%)$, and 10 on the third attempt (1.6\%). Bougie use was documented in 411 on the first attempt (83.4\%), 86 on the second attempt (93.5\%) and 10 on the third attempt (100\%), Cormack and Lehane scores were grade 1: $50.6 \%(n=306)$, grade $2: 29.9 \%(n=181)$, grade 3: $14.4 \%(n=87)$, and grade $4: 3.1 \%(n=19)$. There were three 'impossible' view (0.5\%) and eight 'unrecognisable' views $(1.3 \%)$ recorded. The remaining record had no information on grade of view.

\section{Discussion}

\section{Key results}

We found a first-pass success rate of $81.5 \%$ which is lower than that of other SPCCs (90.8\%) [17] but comparable with that of prehospital physicians $(84.4,84.8 \%)$ [12] [14]. While there is no universally accepted rate of first-pass success for TI, a recent systematic review and meta-analysis incorporating $>$ 40,000 emergency department TIs in 83 institutions worldwide found the average first-pass success to be $84.1 \%$ [22]. Compared with TI in the emergency department, DF-TI in the context of OHCA is often performed on the ground, and complicated by factors such as an unpredictable environment, poor lighting, or an unfamiliar team - all of which may 


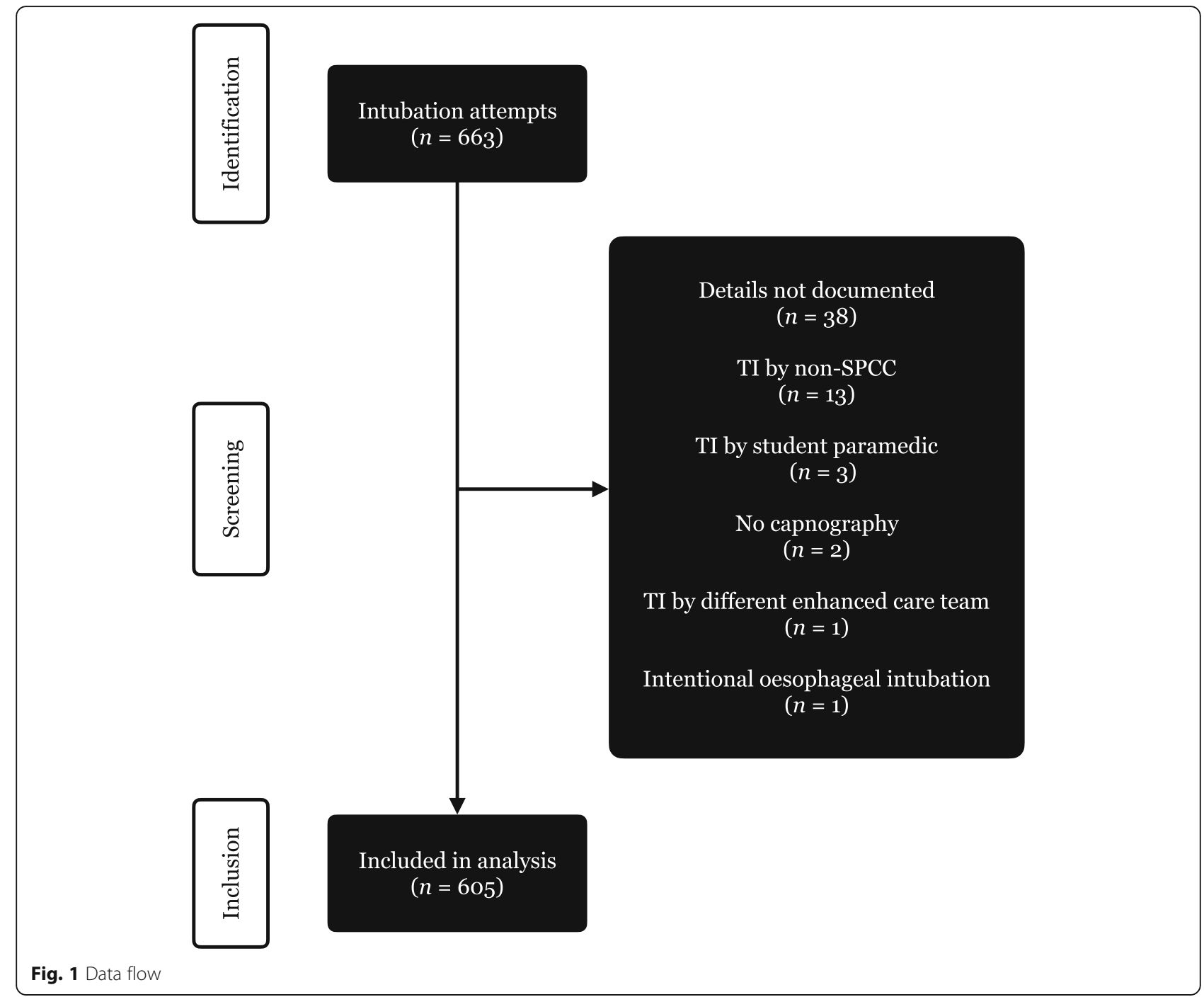

make the procedure more complicated. Although Park et al. [22] found no statistically significant association between the proportion of TI performed during cardiac arrest and first-pass success, a recent study of TI success by prehospital anaesthetists $(n=1006)$ found a significantly lower rate of first-pass success in those receiving cardiopulmonary resuscitation (CPR) versus non-CPR ( $84.4 \%$ vs $91.4 \%, p=0.01)$ [12], suggesting the procedure may be more difficult in this context.

Table 1 Tracheal intubation success

\begin{tabular}{lllcl}
\hline Attempts & $\boldsymbol{n}$ & \% & Combined (\%) & Bougie (\%) $^{\mathbf{a}}$ \\
\hline 1 & 493 & 81.5 & & 83.4 \\
2 & 92 & 15.2 & 96.7 & 93.5 \\
3 & 10 & 1.65 & 98.35 & 100 \\
Not successful & 10 & 1.65 & - &
\end{tabular}

${ }^{a}$ Cases in which bougie use was documented
The most recent European Resuscitation Council and Resuscitation Council UK guidelines $[25,26]$ echo the recommendation by the International Liaison Committee on Resuscitation that only those working within a system that can demonstrate high TI success should use this technique [27] and define "high TI success" as greater than $95 \%$ within two attempts (expert

Table 2 grade of view

\begin{tabular}{lll}
\hline Cormack-Lehane grade & $\boldsymbol{n}$ & $\%$ \\
\hline 1 & 306 & 50.6 \\
2 & 181 & 29.9 \\
3 & 87 & 14.4 \\
4 & 19 & 3.1 \\
Impossible & 3 & 0.5 \\
Unrecognisable & 8 & 1.3 \\
Not recorded & 1 & 0.2 \\
\hline
\end{tabular}


consensus). We found success within two attempts to be 96.7\%, which is again comparable with other enhanced care teams. SPCCs from London Ambulance Service demonstrated success within two attempts for DF-TI in OHCA as 96.4\% [17] while prehospital physicians from London's Air Ambulance reported 98.8\% (89.6\% of records during prehospital emergency anaesthesia, 10.4\% during OHCA). On the other hand, non-specialist paramedics in the 'AIRWAYS-2' trial achieved success within two attempts just $79 \%$ of the time [2].

Our analysis demonstrated a difference between successful TI on the first attempt and that within two attempts $(81.5 \%$ vs $96.7 \%$, respectively). There are several reasons why this may be, not least the complexity of delivering successful TI in an undifferentiated patient within an inherently suboptimal environment. This difference could also be exacerbated by incomplete or suboptimal preparation of the environment, patient, equipment and/or team members involved with the intervention. Although we found successful TI within two attempts to be $96.7 \%$, and overall success of $98.35 \%$ (after three attempts), ensuring full and robust preparation would likely serve to optimise the very best firstpass success achievable, in turn mitigating the opportunity for the patient to suffer deleterious consequences of the care provided.

Although it has been shown that there can be significant inter-operator variability when assessing the laryngoscopy view using the CLCS [20] this detail was included in order to consider any obvious trends. In this analysis 487 (80.5\%) of the records reported a CLCS grade 1 or 2 suggesting less likelihood of complication encountered during TI. Thirty (4.9\%) of all records were described as grade 4 view, unrecognisable, or impossible inevitably resulting in extremely challenging or unsuccessful TI. Analysing the reason for unrecognisable or impossible views was outside the scope of this evaluation.

The use of a bougie to optimise TI success has been widely accepted in prehospital care for a number of years, following a pivotal paper by Driver et al. [9]. A recent secondary analysis of the 'PART' trial data [3] found bougie use for TI during OHCA to increase first-pass success $(52.1 \%$ vs $43.8 \%)$, although this was not significant after adjusting for confounders (OR 1.12, 95\% CI: $0.97-1.39$ ). There is a paucity of evidence supporting the use of a bougie by SPCCs for DF-TI during OHCA, however given the evidence discussed it is the most routinely used TI adjunct in SECAmb (as opposed to a malleable stylet). We found bougie use to be documented in $84.8 \%$ of cases which is far higher than by paramedics in the 'PART' trial (35.9\%) [3]. CCPBase was not optimised to record the reason for not using a bougie and so the remaining $15.2 \%$ may represent records in which either no adjunct or a malleable stylet was used, or in which a bougie was used but not documented.

During data collection we noted a disparity in the way SPCCs record their TI attempts. Some documented the number of attempts by SPCC only while others documented the number of attempts the patient received (including non-SPCC and SPCC). We addressed this by analysing the associated free text, however it may have led to some inaccurate data. Additionally, 38 of the records that were excluded during screening were because the TI data had not been reported and this may have had an impact on our results.

Finally, the data were all self-reported and therefore subject to both recall and reporting bias. As this was a retrospective database review however the SPCCs were not aware of the study design at the time of recording the TI so these biases are likely to be limited.

\section{Interpretation}

Our findings suggest that SECAmb SPCCs can facilitate DF-TI at a standard comparable to that of other enhanced care teams within prehospital care. An overall success rate of $98.35 \%$ is comparable with prehospital emergency anaesthesia data from both physicians (99.8\%) [10] and SPCCs abroad (99.4\%) [8] and is similar to the rate of overall success for the only other UK SPCC data that the authors are aware of (96.4\%) [17].

We demonstrated a lower first-pass success rate than similar services, the reasons for which have been discussed. Our high overall success rate and success within two attempts however meets the definition of "high TI success" recommended by the European Resuscitation Council and Resuscitation Council UK [25, 26] and demonstrates SECAmb SPCCs are both safe and competent at DF-TI.

\section{Generalisability}

Specialist paramedics (critical care) in SECAmb have a different level of education and experience to nonspecialist paramedics, but similar to that of SPCCs in other services. External validity is therefore limited in terms of the paramedic profession, but good in relation to other SPCC teams in the UK and abroad.

\section{Conclusion}

We have demonstrated that SECAmb SPCCs achieved good TI success with high overall success and acceptable first-pass success across the study period. These data show that appropriately trained paramedics can perform DF-TI safely and effectively.

\section{Abbreviations}

CLCS: Cormack-Lehane Classification System; CPR: Cardiopulmonary Resuscitation; DF-TI: Drug-free Tracheal Intubation; OHCA: Out-of-hospital Cardiac Arrest; OR: Odds Ratio; SECAmb: South East Coast Ambulance 
Service; SPCC: Specialist Paramedic (Critical Care); TI: Tracheal Intubation; UK: United Kingdom

\section{Acknowledgements}

With thanks to Alan Cowley, Professor Julia Williams, Professor Tom Quinn, and Dan Cody for their advice and support in designing the study and to Dr. Scott Munro, Dr. Fionna Moore MBE and Dr. Magnus Nelson for their support in completing it.

\section{Authors' contributions}

SHB directed and oversaw the study, was involved in data analysis, applied the final data calculations, and drafted the final article. EA-E was involved in the planning and data analysis. RB was involved in the planning and data analysis. CF was involved in the planning and data analysis. SH was involved in the planning and data analysis and drafted the final article. LH was involved in the planning and data analysis. BP was involved in the planning and data analysis and drafted the final article. SP was involved in the planning and data analysis. ST was involved in the planning and data analysis. PW was involved in the planning and data analysis. All authors have read and approved the final manuscript.

\section{Funding}

None.

\section{Availability of data and materials}

The datasets used and/or analysed during the current study have not been made publicly available but have been retained for 1 year (until 30/04/2022) and are available from the corresponding author on reasonable request.

\section{Declarations}

\section{Ethics approval and consent to participate}

The proposed study met National Health Service (NHS) criteria for a service evaluation [19] and was not considered research by the NHS Health Research Authority.

Administrative permission to access the datasets analysed was granted by SECAmb's Information Governance team, for the purpose of service evaluation.

\section{Consent for publication}

Not applicable.

\section{Competing interests}

All authors are currently employed as SPCCs within SECAmb. The authors declare that they have no other competing interests.

\section{Received: 9 August 2021 Accepted: 28 October 2021}

Published online: 20 November 2021

\section{References}

1. Association of Anaesthetists of Great Britain and Ireland (AAGBI). Prehospital Anaesthesia. London: The Association of Anaesthetists of Great Britain and Ireland; 2008

2. Benger JR, Kirby K, Black S, Brett SJ, Clout M, Lazaroo MJ, et al. Effect of a strategy of a Supraglottic airway device vs tracheal intubation during outof-hospital cardiac arrest on functional outcome: the AIRWAYS-2 randomized clinical trial. J Am Med Assoc. 2018;320(8):779-91. https://doi. org/10.1001/jama.2018.11597.

3. Bonnette AJ, Aufderheide TP, Jarvis JL, Lesnick JA, Nichol G, Carlson JN, et al. Bougie-assisted endotracheal intubation in the pragmatic airway resuscitation trial. Resuscitation. 2021;158:215-9. https://doi.org/10.1016/j. resuscitation.2020.11.003

4. College of Paramedics. Consensus statement: a framework for safe and effective intubation by paramedics, s.l.: College of Paramedics; 2018a.

5. College of Paramedics. Post-registration - paramedic career framework. 4th ed. Bridgwater: College of Paramedics; 2018b.

6. Cormack RS, Lehane J. Difficult tracheal intubation in obstetrics. Anaesthesia. 1984;39(11):1105-11. https://doi.org/10.1111/j.1365-2044.1984.tb08932.x.

7. Cowley A, Durham M, Aldred D, Crabb R, Crouch P, Heywood A, et al. Presence of a pre-hospital enhanced care team reduces on scene time and improves triage compliance for stab trauma. Scand J Trauma Resusc Emerg Med. 2019;27(86):1-6. https://doi.org/10.1186/s13049-019-0661-z.

8. Delorenzo A, St Clair T, Andrew E, Bernard S, Smith K. Prehospital rapid sequence intubation by intensive care flight paramedics. Prehosp Emerg Care. 2018;22(5):1-7. https://doi.org/10.1080/10903127.2018.1426666.

9. Driver B, Dodd K, Klein LR, Buckley R, Robinson A, JW MG, et al. The bougie and first-pass success in the emergency department. Ann Emerg Med. 2017; 70(4):473-8.

10. Harris T, Lockey D. Success in physician prehospital rapid sequence intubation: what is the effect of base speciality and length of anaesthetic training? Emerg Med J. 2011;28(3):225-9. https://doi.org/10.1136/emj.2009. 088302.

11. Hasegawa K, Shigemitsu K, Hagiwara Y, Chiba T, Watase H, Brown CA 3rd, et al. Association between repeated intubation attempts and adverse events in emergency departments: an analysis of a multicenter prospective observational study. Ann Emerg Med. 2012;60(6):749-54. https://doi.org/10.1 016/j.annemergmed.2012.04.005.

12. Hossfeld, B. et al. First pass success of tracheal intubation using the C-MAC PM videolaryngoscope as first-line device in prehospital cardiac arrest compared with other emergencies. Eur J Anaesthesiol. 2021;38(8):806-812.

13. Kaji AH, Schriger $D$, Green S. Looking through the Retrospectoscope: reducing bias in emergency medicine chart review studies. Ann Emerg Med. 2014;64(3):292-8. https://doi.org/10.1016/j.annemergmed.2014.03.025.

14. Knapp J, Eberle B, Bernhard M, Theiler L, Pietsch U, Albrecht R. Analysis of tracheal intubation in out-of- hospital helicopter emergency medicine recorded by video laryngoscopy. Scand J Trauma Resusc Emerg Med. 2021; 29(49):1-10. https://doi.org/10.1186/s13049-021-00863-9.

15. Lafferty KA, Dillinger R. Rapid sequence intubation, [online] available at: https://emedicine.medscape.com/article/80222-overview [accessed $10 \mathrm{Sep}$ 2020]; 2020.

16. Lockey DJ, Crewsdon K, Lossius HM. Pre-hospital anaesthesia: the same but different. Br J Anaesth. 2014;113(2):211-9. https://doi.org/10.1093/bja/aeu2 05.

17. Mclntyre I, Faulkner M, Edwards T. Advanced airway management by advanced paramedic practitioners in critical care (APP-CC) in a UK ambulance service: a retrospective review. London: London Ambulance Service NHS Trust; 2019.

18. Medic One Systems. Home; n.d. [Online] Available at: http://www. mediconesystems.com [Accessed 12 Aug 2020]

19. Norfolk and Suffolk NHS Foundation Trust. Is my project research, evaluation or audit? 2014. [Online] Available at: https://www.nsft.nhs.uk/Get-involved/ Documents/ls\%20my\%20Project\%20Research\%20Evaluation\%20or\%20Audit. pdf [Accessed 29 Jun 2020]

20. Ochroch EA, Hollander JE, Kush S, Shofer FS, Levitan RM. Assessment of laryngeal view: percentage of glottic opening score vs Cormack and Lehane grading. Can J Anaesth. 1999;46(10):987-90. https://doi.org/10.1007/BF03 013137.

21. Pallin DJ. Maybe paramedics should not perform endotracheal intubation. NEJM journal watch; 2018

22. Park L, Zeng I, Brainard A. Systematic review and meta-analysis of firstpasssuccess rates in emergency department intubation: creating a benchmark for emergency airway care. Emerge Med Australas. 2017;29(1): 40-7. https://doi.org/10.1111/1742-6723.12704.

23. Perkins GD, Lall R, Quinn T, Deakin CD, Cooke MW, Horton J, et al. Mechanical versus manual chest compression for out-of-hospital cardiac arrest (PARAMEDIC): a pragmatic, cluster randomised controlled trial. Lancet. 2015;285(9972):947-55. https://doi.org/10.1016/S0140-6736(14)61886-9.

24. Sakles JC, Chiu S, Mosier J, Walker C, Stolz U. The importance of first pass success when performing Orotracheal intubation in the emergency department. Acad Emerg Med. 2013;20(1):71-8. https://doi.org/10.1111/a cem. 12055

25. Soar J, et al. Adult advanced life support guidelines; 2021b. [online] Available at: https://www.resus.org.uk/library/2021-resuscitation-guidelines/a dult-advanced-life-support-guidelines [Accessed 18 May 2021]

26. Soar J, Böttiger BW, Carli P, Couper K, Deakin CD, Djärv T, et al. European resuscitation council guidelines 2021: adult advanced life support Resuscitation. 2021a;161:115-51. https://doi.org/10.1016/j.resuscitation.2021. 02.010 .

27. Soar J, Maconochie I, Wyckoff MH, Olasveengen TM, Singletary EM, Greif R, et al. 2019 international consensus on cardiopulmonary resuscitation and emergency cardiovascular care science with treatment recommendations. 
Circulation. 2019;140(24):e826-80. https://doi.org/10.1161/CIR. 0000000000000734 .

28. Soar J, Nolan J P, Bottinger B W, et al. European Resuscitation Council Guidelines for Resuscitation 2015 Section 3. Adult advanced life support. Resuscitation. 2015;95:100-47. https://doi.org/10.1016/j.resuscitation.2015.07. 016.

29. von Vopelius-Feldt J, Brandling J, Benger J. Variations in stakeholders' priorities and views on randomisation and funding decisions in out-ofhospital cardiac arrest: an exploratory study. Health Science Reports. 2018; 1(e78):1-10. https://doi.org/10.1002/hsr2.78.

30. Wang HE, Schmicker RH, Daya MR, Stephens SW, Idris AH, Carlson JN, et al. Effect of a strategy of initial laryngeal tube insertion vs endotracheal intubation on 72-hour survival in adults with out-of-hospital cardiac arrest a randomized clinical trial. JAMA. 2018;320(8):769-78. https://doi.org/10.1001/ jama.2018.7044

\section{Publisher's Note}

Springer Nature remains neutral with regard to jurisdictional claims in published maps and institutional affiliations.

Ready to submit your research? Choose BMC and benefit from:

- fast, convenient online submission

- thorough peer review by experienced researchers in your field

- rapid publication on acceptance

- support for research data, including large and complex data types

- gold Open Access which fosters wider collaboration and increased citations

- maximum visibility for your research: over $100 \mathrm{M}$ website views per year

At BMC, research is always in progress.

Learn more biomedcentral.com/submissions 